\title{
ANTIOXIDANT AND ANTI-INFLAMMATORY EFFECTS OF CURCUMIN CONTRIBUTE INTO ATTENUATION OF ACUTE GENTAMICIN-INDUCED NEPHROTOXICITY IN RATS
}

\author{
HAYDER M AL-KURAISHY*, ALI I AL-GAREEB, HUDA ABDULBAKI RASHEED
}

Department of Clinical Pharmacology, Medicine and Therapeutic, Medical Faculty, College of Medicine, Al-Mustansiriya University, Baghdad, Iraq. Email: hayderm36@yahoo.com

Received: 22 November 2018, Revised and Accepted: 31 December 2018

\section{ABSTRACT}

Objectives: Nephrotoxicity is a renal-specific situation in which the excretion of toxic metabolites is reduced due to toxic agents and drugs. Gentamicin is an antibiotic belongs to aminoglycoside group which may induce nephrotoxicity due to induction of oxidative stress. Curcumin is a component of traditional medicine with significant nephroprotective effect. Therefore, the objective of the present study was to evaluate the nephroprotective effect of curcumin on gentamicin-induced nephrotoxicity.

Methods: A total of 30 male Sprague-Dawley rats were used which divided into Group 1 ( $\mathrm{n}=10$ ): Rats treated with distilled water 5 ml/kg plus normal saline $5 \mathrm{ml} / \mathrm{kg}$ for 12 days, Group 2 ( $\mathrm{n}=10$ ): Rats treated with distilled water $5 \mathrm{ml} / \mathrm{kg}$ plus gentamicin $100 \mathrm{mg} / \mathrm{kg}$ for 12 days, and Group 3 (n=10): Rats treated with curcumin $100 \mathrm{mg} / \mathrm{kg}$ plus gentamicin $100 \mathrm{mg} / \mathrm{kg}$ for 12 days. Blood urea, serum creatinine, malondialdehyde (MDA), kidney injury molecule (KIM-1), and cystatin-C were measured in both control and experimental groups.

Results: Rats treated with gentamicin showed nephrotoxicity as evident by significant elevation in blood urea, serum creatinine, KIM-1, MDA, and cystatin-C sera levels. Curcumin leads to significant reduction of blood urea and serum creatinine compared to gentamicin group, $\mathrm{p}<0.05$. Curcumin also reduced MDA, KIM-1, and cystatin-C sera levels significantly compared to gentamicin group, $\mathrm{p}<0.01$.

Conclusion: Curcumin produced significant nephroprotective effect on gentamicin-induced nephrotoxicity through modulation of oxidative stress and inflammatory biomarkers.

Keywords: Nephrotoxicity, Gentamicin, Curcumin.

(c) 2019 The Authors. Published by Innovare Academic Sciences Pvt Ltd. This is an open access article under the CC BY license (http://creativecommons. org/licenses/by/4. 0/) DOI: http://dx.doi.org/10.22159/ajpcr.2019.v12i3.30875

\section{INTRODUCTION}

Nephrotoxicity is a renal-specific condition in which the flow of toxic metabolites does not go resourcefully due to toxic agents and drugs. Approximately $20 \%$ of nephrotoxicity is caused by drugs; this fraction is augmented in the elderly due to the rise in the life span [1].

Gentamicin is an antibiotic of aminoglycoside group, used for the treatment of different bacterial infections, $90 \%$ of administrated gentamicin is excreted unchanged in the proximal renal tubules which may lead to extensive renal tubular necrosis at a higher dose [2].

Excessive production of reactive oxygen species and free radicals is the chief mechanism for gentamicin-induced nephrotoxicity. Definitely, gentamicin induces the expression of transporter proteins at proximal renal tubules causing free radical generations [3]. Therefore, gentamicin-induced nephrotoxicity is a multifaceted phenomenon which previously linked to the oxidative stress only.

Chronic and high dose of gentamicin provokes in vitro and in vivo free radical productions and induction of oxidative stress. Gentamicin triggers mitochondrial superoxide anions causing generation of hydroxyl radicals [1].

Moreover, antioxidant agents demonstrate a renoprotective effect in gentamicin-induced nephrotoxicity. One of these plants called curcumin which is a member of the ginger family. Curcumin is the main curcuminoids present in the turmeric which contains virtually $77 \%$ curcumin [4].

Curcumin's effect on free radicals is happened by different mechanism; it scavenges free radicals such as reactive oxygen species and reactive nitrogen species. As well, curcumin inhibits reactive oxygen speciesgenerating enzymes including lipoxygenase, cyclooxygenase, and xanthine oxidase [5].

Therefore, theaim of the presentstudy was to assess the nephroprotective effect of curcumin on gentamicin-induced nephrotoxicity.

\section{METHODS}

A total number of 30 Sprague-Dawley male rats were used, rats age ranges from 3 to 4 months and their body weight ranges from 200 to $400 \mathrm{~g}$. The animals were placed at appropriate temperature of $22-25^{\circ} \mathrm{C}$ with $12 / 12 \mathrm{hrs}$, light-dark cycle. This study was permitted by specific Scientific Adjudicators and Ethical Committee in the Medical Board College of Medicine, Al-Mustansiriya, Baghdad, Iraq. Humane care for animals was according to the guide to the care and the use of laboratory animal. The rats were randomly divided into three groups: Group 1(n=10): Rats treated with distilled water $(5 \mathrm{ml} / \mathrm{kg}, \mathrm{p} .0)$ for 12 days, on day 6-12, they received an intraperitoneal (i.p.) injection of normal saline ( $5 \mathrm{ml} / \mathrm{kg}$ ) daily. Group 2 ( $\mathrm{n}=10)$ : Rats treated with distilled water $(5 \mathrm{ml} / \mathrm{kg}$, p.o) for 12 days, and on day from 6 to 12 , they received gentamicin $100 \mathrm{mg} / \mathrm{kg}$, i.p. Group 3 (n=10): Rats treated with curcumin (100 mg/kg, p.o) for 12 days, and on day 6-12, they received gentamicin $100 \mathrm{mg} / \mathrm{kg}$, i.p at an interval of $1 \mathrm{~h}$. On the $13^{\text {th }}$ day, rats were decapitated under light anesthesia and blood samples were centrifugated at $3500 \mathrm{rpm} / 15 \mathrm{~min}$. The method was according to Singh et al. method [6].

All drugs were purchased from private pharmacy gentamicin ampoule (Garamycin $80 \mathrm{mg}$ Schering-Plough, USA) and curcumin tablet (Curcuma longa $500 \mathrm{mg}$ tablet $95 \%$ curcuminoids, rhizome, VEGGIE CAPS., 04216CUR120, Los Angeles, USA). 
Table 1: Renal function and renal injury biomarkers in gentamicin-induced nephrotoxicity

\begin{tabular}{lll}
\hline Variables & Control $(\mathbf{n = 1 0})$ & Gentamicin (n=10) \\
\hline Blood urea $(\mathrm{mg} / \mathrm{dL})$ & $41.83 \pm 7.46$ & $56.87 \pm 9.33$ \\
Serum creatinine $(\mathrm{mg} / \mathrm{dL})$ & $0.70 \pm 0.14$ & $1.08 \pm 0.40$ \\
MDA $(\mathrm{ng} / \mathrm{mL})$ & $289.85 \pm 44.18$ & $408.11 \pm 145.8$ \\
KIM-1 $(\mathrm{pg} / \mathrm{mL})$ & $73.78 \pm 16.29$ & $354.98 \pm 46.38$ \\
Cystatin-C ng/ml & $0.024 \pm 0.0005$ & $0.028 \pm 0.001$ \\
\hline
\end{tabular}

Data are expressed as mean \pm SD * $\mathrm{p}<0.05 ; \mathrm{p}<0.01$, unpaired $t$-test, MDA: Malondialdehyde; KIM-1: Kidney injury molecule-1, Cys-C: Cystatin

Table 2: Effect of curcumin on the biochemical and renal injury biomarkers in gentamicin-induced nephrotoxicity

\begin{tabular}{lll}
\hline Variables & Gentamicin (n=10) & Curcumin (n=10) \\
\hline Blood urea (mg/dL) & $56.87 \pm 9.33$ & $46.25 \pm 8.47$ \\
Serum creatinine (mg/dL) & $1.08 \pm 0.40$ & $0.77 \pm 0.18$ \\
MDA (ng/mL) & $408.11 \pm 145.8$ & $208.11 \pm 88.8$ \\
KIM-1 (pg/mL) & $354.98 \pm 46.38$ & $131.79 \pm 31.22$ \\
Cystatin-C ng/ml & $0.028 \pm 0.001$ & $0.03^{*}$ \\
\hline
\end{tabular}

Data are expressed as mean \pm SD $* \mathrm{p}<0.05$; $<<0.01$, unpaired $t$-test, MDA: Malondialdehyde, KIM-1: Kidney injury molecule-1; Cys-C: Cystatin

\section{Assessment of renal injury biomarkers}

Blood urea and serum creatinine were assessed by autoanalyzer. Biomarkers of renal injury including serum of malondialdehyde (MDA), kidney injury molecules (KIM-1), and cystatin- $C$ were measured by ELISA kit methods according to the instruction of the manufacturer.

\section{Statistics}

Data of the present study were presented as mean \pm SD. Unpaired Student's $t$-test was used to detect the level of significance between control and treated groups. p value was regarded as statistically significant when it is $<0.05$.

\section{RESULTS}

Blood urea was raised significantly in gentamicin group $(56.87 \pm 9.33 \mathrm{mg} / \mathrm{dl})$ compared tothecontrol $(41.83 \pm 7.46 \mathrm{mg} / \mathrm{dl}) \mathrm{p}=0.007$, as well, serum creatinine was increased significantly in gentamicin group $(1.08 \pm 0.40 \mathrm{mg} / \mathrm{dl})$ compared to control $(0.70 \pm 0.14 \mathrm{mg} / \mathrm{dl})$, $\mathrm{p}=0.04$.

Regarding the oxidative stress and endogenous antioxidant capacity, there was insignificant increase in the MDA serum levels in gentamicin group $(408.11 \pm 145.8 \mathrm{ng} / \mathrm{ml})$ compared to the control $(289.85 \pm 44.18 \mathrm{ng} / \mathrm{ml}), \mathrm{p}=0.08$. Moreover, $\mathrm{KIM}-1$ was significantly increased in gentamicin group $(354.98 \pm 46.38 \mathrm{pg} / \mathrm{ml})$ compared to the control (73.78 \pm 16.29$), p=0.0001$. Certainly, cystatin-C serum level was significantly increased during induction of nephrotoxicity by gentamicin from $0.024 \pm 0.0005 \mathrm{ng} / \mathrm{ml}$ in the control group to $0.0280 \pm 0.0016 \mathrm{ng} / \mathrm{ml}$ in the experimental group, $\mathrm{p}=0.01$ (Table 1 ).

Curcumin leads to significant reduction of blood urea and serum creatinine compared to gentamicin group, $\mathrm{p}<0.05$. Curcumin also reduced MDA, KIM-1, and cystatin-C sera levels significantly compared to gentamicin group, $\mathrm{p}<0.01$ (Table 2).

\section{DISCUSSION}

Gentamicin is a bactericidal antibiotic used alone or in combination with $\beta$-lactam antibiotics for the treatment of different bacterial infections. In spite of these possessions, gentamicin therapy leads to nephrotoxicity in about $30 \%$ of treated cases even after precise monitoring [7].

The present study definitely illustrated that gentamicin was proficient to induced experimental nephrotoxicity in rats through significant elevation in blood urea and serum creatinine which correspond with a recent study [8].

It has been established that the production of free radicals and induction of oxidative stress are the main important pathway of gentamicin- induced nephrotoxicity. Overproduction of reactive oxygen species is linked with depletion of proximal renal tubules antioxidant potential which subsequently leads to lipid peroxidation and tubular damages [9].

Therefore, serum level of MDA was elevated in different models of gentamicin-induced nephrotoxicity as illustrated by Hajihashemi et al. study [10].

The present study as well illustrated significant consequence of gentamicin in rising KIM-1 levels as inconsistence with Luo et al. study that demonstrated both KIM-1 and NGAL sera levels are sensitive and specific biomarkers in gentamicin-induced nephrotoxicity. The augmentation in those biomarkers is due to progressive gene expression of KIM-1 and NGAL [11].

Remarkably, the imbalance in the production of free radicals and the shortage to detoxify these free radicals by antioxidants lead to induction of oxidative stress. Curcumin has a higher antioxidant potential against free radicals due to phenolic and flavonoid compounds [12].

Furthermore, Trujillo et al. study confirmed that curcumin has a significant nephroprotective effect due to antioxidant and/or preservation of endogenous antioxidant capacity, antiinflammatory, free radical scavenging effects, as well as preservation of renal mitochondrial redox balance during acute and chronic nephrotoxicity [13].

Recently, Mercantepe et al. illustrated significant nephroprotective effect of curcumin in attenuation of cisplatin-induced nephrotoxicity and acute kidney injury through modulation of reactive oxygen species and augmentation of endogenous antioxidant potentials [14].

Besides, curcumin significantly reduces renal tubular injury biomarkers due to significant nephroprotective effect in gentamicininduced nephrotoxicity as supported by Kim et al. study that demonstrated administration of $100 \mathrm{mg} / \mathrm{kg} /$ day of curcumin was able to reduced KIM-1 and NGAL sera levels significantly in cadmium-induced nephrotoxicity [15]. As well, Wu et al. showed important effect of curcumin in reduction of inflammatory and renal tubular injury biomarkers during glycerol-induced acute nephrotoxicity [16].

Interestingly, the present study proved the protective effect of curcumin on the glomerular function through reduction of cystatin-C serum levels when coadministered with gentamicin. Curcumin significantly reduced cystatin-C serum levels in both acute and chronic renal injury due to significant nephroprotective effect of curcumin through modulation of 
glomerular blood flow and regulation of intraglomerular pressure and inflammations $[17,18]$.

\section{CONCLUSION}

Curcumin produced significant nephroprotective effect in gentamicininduced nephrotoxicity through modulation of oxidative stress and inflammatory biomarkers.

\section{AUTHORS' CONTRIBUTIONS}

All authors contribute equally in data collection, experimental design, interpretation, statistical analysis, literature review, manuscript preparation, and review.

\section{CONFLICTS OF INTEREST}

There are no conflicts of interest to declare.

\section{REFERENCES}

1. Bhatia A, Chadha R, Jain UK, Singh G. Amleorative role of esculetinmediated renoprotection against gentamicin-induced nephrotoxicity and possible involvement of N-methyl-D-aspartate receptors. Asian J Pharm Clin Res 2017;10:322-8.

2. Virani SH, Bhatt SH, Saini MA, Saxena K. Aloe vera attenuates gentamicin-induced nephrotoxicity in Wistar albino rats: Histopathological and biochemical changes. Asian J Pharm Clin Res 2016;9:113-7.

3. Aly HA, Hassan MH. Potential testicular toxicity of gentamicin in adult rats. Biochem Biophys Res Commun 2018;497:362-7.

4. Athira GK, Jyothi AN. Preparation and characterization of curcumin loaded cassava starch nanoparticles with improved cellular absorption. Int J Pharm Pharm Sci 2014;6:171-6.

5. Puneeth HR, Sharada AC. Antioxidant and hypoglycemic effects of curcumin pyrazole derivatives. Int J Pharm Pharm Sci 2015;7:244-9.

6. Singh AP, Junemann A, Muthuraman A, Jaggi AS, Singh N, Grover $\mathrm{K}$, et al. Animal models of acute renal failure. Pharmacol Rep 2012;64:31-44.
7. Teslariu O, Pasca AS, Mititelu-Tartau L, Schiriac CE, Gales C, Saftencu PM, et al. The protective effects of zinc in experimental gentamicin induced acute renal failure in rats. J Physiol Pharmacol 2016;67:751-7.

8. Abd-Elhamid TH, Elgamal DA, Ali SS, Ali FE, Hassanein EH, El-Shoura EA, et al. Reno-protective effects of ursodeoxycholic acid against gentamicin-induced nephrotoxicity through modulation of NF- $\mathrm{BB}$, eNOS and caspase-3 expressions. Cell Tissue Res 2018;374:367-87.

9. Al-Kuraishy HM, Al-Gareeb AI. Potential effects of pomegranate on lipid peroxidation and pro-inflammatory changes in daunorubicininduced cardiotoxicity in rats. Int J Prev Med 2016;7:85.

10. Hajihashemi S, Hamidizad Z, Rahbari A, Ghanbari F, Motealeghi ZA. Effects of cobalamin (Vitamin B12) on gentamicin induced nephrotoxicity in rat. Drug Res (Stuttg) 2017;67:710-8.

11. Luo QH, Chen ML, Sun FJ, Chen ZL, Li MY, Zeng W, et al. KIM-1 and NGAL as biomarkers of nephrotoxicity induced by gentamicin in rats. Mol Cell Biochem 2014;397:53-60.

12. Al-Kuraishy HM, Al-Gareeb AI, Al-Maiahy TJ. Concept and connotation of oxidative stress in preeclampsia. J Lab Physicians 2018;10:276.

13. Trujillo J, Chirino YI, Molina-Jijón E, Andérica-Romero AC, Tapia E, Pedraza-Chaverrí J, et al. Renoprotective effect of the antioxidant curcumin: Recent findings. Redox Biol 2013;1:448-56.

14. Mercantepe F, Mercantepe T, Topcu A, Y1lmaz A, Tumkaya L. Protective effects of amifostine, curcumin, and melatonin against cisplatin-induced acute kidney injury. Naunyn Schmiedebergs Arch Pharmacol 2018;391:915-31.

15. Kim KS, Lim HJ, Lim JS, Son JY, Lee J, Lee BM, et al. Curcumin ameliorates cadmium-induced nephrotoxicity in sprague-dawley rats. Food Chem Toxicol 2018;114:34-40.

16. Wu J, Pan X, Fu H, Zheng Y, Dai Y, Yin Y, et al. Effect of curcumin on glycerol-induced acute kidney injury in rats. Sci Rep 2017;7:10114.

17. Ali BH, Al-Salam S, Al Suleimani Y, Al Kalbani J, Al Bahlani S, Ashique $\mathrm{M}$, et al. Curcumin ameliorates kidney function and oxidative stress in experimental chronic kidney disease. Basic Clin Pharmacol Toxicol 2018;122:65-73.

18. Topcu-Tarladacalisir Y, Sapmaz-Metin M, Karaca T. Curcumin counteracts cisplatin-induced nephrotoxicity by preventing renal tubular cell apoptosis. Ren Fail 2016;38:1741-8. 